\title{
Sequence influence of nonidentical InGaAsP quantum wells on broadband characteristics of semiconductor optical amplifiers-superluminescent diodes
}

\author{
Ching-Fuh Lin and Bing-Ruey Wu \\ Institute of Electro-Optical Engineering and Department of Electrical Engineering, National Taiwan University, Taipei, Taiwan
}

Lih-Wen Laih and Tien-Tsorng Shih

Telecommunication Laboratory, Chunghua Telecom Co., Ltd., Yang-Mei, Taoyuan, Taiwan

Received February 12, 2001

\begin{abstract}
Extremely broadband emission is obtained from semiconductor optical amplifiers-superluminescent diodes with nonidentical quantum wells made of $\operatorname{InGaAsP} / \mathrm{InP}$ materials. The well sequence is experimentally shown to have a significant influence on the emission spectra. With the three $\operatorname{In}_{0.67} \mathrm{Ga}_{0.33} \mathrm{As}_{0.72} \mathrm{P}_{0.28}$ quantum wells near the $n$-cladding layer and the two $\mathrm{In}_{0.53} \mathrm{Ga}_{0.47}$ As quantum wells near the $p$-cladding layer, all bounded by $\mathrm{In}_{0.86} \mathrm{Ga}_{0.14} \mathrm{As}_{0.3} \mathrm{P}_{0.7}$ barriers, the emission spectrum could cover from less than 1.3 to nearly $1.55 \mu \mathrm{m}$, and the FWHM could be near $300 \mathrm{~nm}$. (C) 2001 Optical Society of America

OCIS codes: $250.5980,060.4510,160.6000,160.3380,230.0250$.
\end{abstract}

Broadband characteristics are highly desired for semiconductor lasers and amplifiers for applications in optical communication. However, conventional semiconductor optical amplifiers (SOAs)-superluminescent diodes (SLDs) for optical fiber communication have a bandwidth of $\sim 50 \mathrm{~nm}$, which is much narrower than the usable range of optical fibers. Therefore, schemes for broadening SOA-SLD bandwidth are attractive. Quantum-well (QW) engineering is a convenient, widely used way to broaden the bandwidth of SOAs-SLDs. This scheme includes using a single QW with simultaneous transitions of $n=1$ and $n=2$ states $^{1,2}$ and using nonidentical QWs. ${ }^{3-6}$ Because the simultaneous transitions of $n=1$ and $n=2$ energy states in identical QWs rely strongly on the device length, ${ }^{1,2}$ nonidentical multiple quantum wells (MQWs) were recently been widely used for broadband purposes. ${ }^{4-7}$

However, nonuniform carrier distribution among the MQWs had been theoretically predicted., ${ }^{8,9}$ Experimental evidence was also indirectly obtained from the characteristics of laser diodes. ${ }^{10,11}$ Nonuniform carrier distribution means that each $\mathrm{QW}$ of the MQW structure accumulates a different number of carriers, so their corresponding emission intensities are not equal. Then, the overlap of the individual spectrum from each type of QW, weighted by its corresponding emission intensity, does not directly result in a broadband spectrum. Thus the design of nonidentical MQW structures for broadband purposes is not intuitively straightforward, and more studies on the spectral behavior of the nonidentical MQWs are necessary. In this Letter we report the investigation of emission spectra from SOAs-SLDs that are strongly influenced by the well sequence of the nonidentical MQWs owing to the nonuniform carrier distribution. Extremely broadband emission is still possible for a certain well sequence. With proper placement of the nonidentical MQWs, the emission spectrum can cover from 1.3 to $1.55 \mu \mathrm{m}$, with what is believed to be a record bandwidth near $300 \mathrm{~nm}$. In addition, we have discovered that more carriers are accumulated in the QWs near the $n$-cladding layer in our design. This is contrary to the past conclusion that the slow mobility of holes causes more carriers to be trapped in QWs near the $p$-cladding layer. ${ }^{10}$ The reason for the opposite carrier distribution is also discussed.

The designed QW structures are shown in Fig. 1. A separate confinement heterostructure $(\mathrm{SCH})$ is formed in connection with the wells. The SCH layer has a thickness of $120 \mathrm{~nm}$. The wells are separated by 15 -nm-wide $\mathrm{In}_{0.86} \mathrm{Ga}_{0.14} \mathrm{As}_{0.3} \mathrm{P}_{0.7}$ barriers. In sample $\mathrm{A}$ the three 6.0-nm $\operatorname{In}_{0.67} \mathrm{Ga}_{0.33} \mathrm{As}_{0.72} \mathrm{P}_{0.28}$ QWs are placed near the $n$-cladding layer, whereas the two 8.7-nm $\mathrm{In}_{0.53} \mathrm{Ga}_{0.47} \mathrm{As} \mathrm{QWs}$ are placed near the $p$-cladding layer. Sample B has the opposite
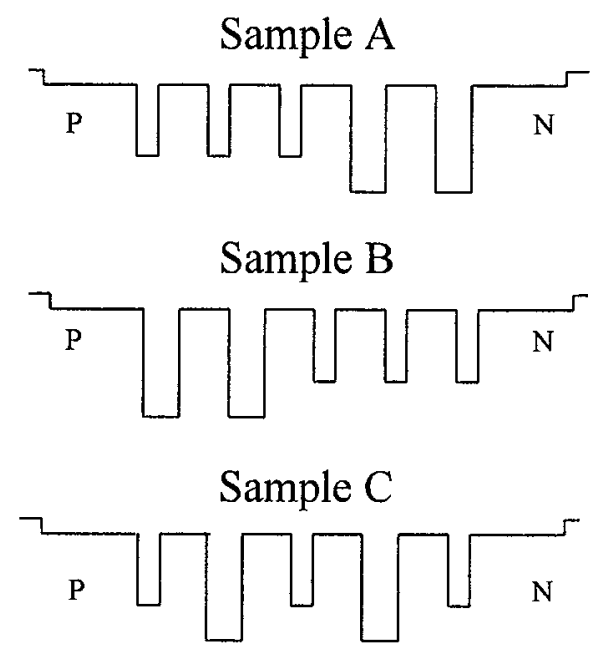

Fig. 1. Designed QW structures: wide QW, $\mathrm{In}_{0.53} \mathrm{Ga}_{0.47} \mathrm{As}, 8.7 \mathrm{~nm}$; narrow $\mathrm{QW}, \mathrm{In}_{0.67} \mathrm{Ga}_{0.33} \mathrm{As}_{0.72} \mathrm{P}_{0.28}$, $6.0 \mathrm{~nm}$; barrier, $\mathrm{In}_{0.86} \mathrm{Ga}_{0.14} \mathrm{As}_{0.3} \mathrm{P}_{0.7}, 15 \mathrm{~nm}$; $\mathrm{SCH}$ region, $\mathrm{In}_{0.86} \mathrm{Ga}_{0.14} \mathrm{As}_{0.3} \mathrm{P}_{0.7}, 120 \mathrm{~nm}$. 
sequence. Sample $\mathrm{C}$ has each $\mathrm{In}_{0.53} \mathrm{Ga}_{0.47} \mathrm{As}$ QW placed between the $\operatorname{In}_{0.67} \mathrm{Ga}_{0.33} \mathrm{As}_{0.72} \mathrm{P}_{0.28}$ QWs. These QW structures were grown by metal-organic chemical-vapor deposition.

Tilted-stripe SLDs were fabricated on the substrates described above. The 5- $\mu \mathrm{m}$ ridge waveguide of the SLDs was tilted $5^{\circ}$ from the normal to the cleaved facet. The tilted-stripe structure could reduce the light reflection from the cleaved facet, so the influence of the Fabry-Perot resonance could be minimized. The length the device was $\sim 500 \mu \mathrm{m}$. Typical processing techniques were used for device fabrication. The ridge waveguide was created by reactive-ion etching. Etching was stopped at $\sim 100 \mathrm{~nm}$ above the SCH layer. The fabrication was completed by $n$-contact metallization. Then the devices were cleaved apart. No facet coatings were applied to the devices.

The emission energies of the 6.0-nm $\mathrm{In}_{0.67} \mathrm{Ga}_{0.33} \mathrm{As}_{0.72} \mathrm{P}_{0.28} \mathrm{QW}$ and 8.7-nm $\mathrm{In}_{0.53} \mathrm{Ga}_{0.47} \mathrm{As}$ QW were calculated with the Luttinger-Kohn method. ${ }^{12}$ Table 1 shows the emission wavelengths corresponding to the calculated energy levels. $\mathrm{In}_{0.67} \mathrm{Ga}_{0.33} \mathrm{As}_{0.72} \mathrm{P}_{0.28} \quad \mathrm{QW}$ and $\mathrm{In}_{0.53} \mathrm{Ga}_{0.47} \mathrm{As}$ QWs have three and two quantized energy levels in the design, respectively. Figure 2 shows the measured emission spectra of the three samples for different injection-current levels. Very distinct features of the emission spectra from the three samples are clearly shown. Because it is usually difficult to match the material ingredients to the designed wavelengths exactly, the emission peaks are slightly off the calculated values. However, the main features are still preserved very well. The emission peaks are also influenced by the band-filling effect for large current injection.

For sample A, emission at low injection current occurs at the wavelength corresponding to the $n=1$ transition in the 8.7-nm $\mathrm{In}_{0.53} \mathrm{Ga}_{0.47} \mathrm{As}$ QWs, which are close to the $n$-cladding layer. When the injection current increases, the emission spectrum is first broadened owing to the simultaneous transitions of $n=1$ and $n=2$ states. The emission contribution from the 6.0-nm $\mathrm{In}_{0.67} \mathrm{Ga}_{0.33} \mathrm{As}_{0.72} \mathrm{P}_{0.28} \mathrm{QWs}$ is not obvious until the injection current is increased to more than $400 \mathrm{~mA}$. For sample B, emission at low injection current occurs at the wavelength corresponding to the $n=1$ transition in the 6.0-nm $\operatorname{In}_{0.67} \mathrm{Ga}_{0.33} \mathrm{As}_{0.72} \mathrm{P}_{0.28}$ QWs, which are also close to the $n$-cladding layer. Further increase of the injection current does not obviously change the emission wavelength. The slight blueshift of the peak wavelength is a result of the band-filling effect in the $\operatorname{In}_{0.67} \mathrm{Ga}_{0.33} \mathrm{As}_{0.72} \mathrm{P}_{0.28} \mathrm{QWs}$. For sample C, emission also first occurs at the wavelength corresponding to the $n=1$ transition in the 8.7-nm $\mathrm{In}_{0.53} \mathrm{Ga}_{0.47} \mathrm{As} \mathrm{QWs}$ when the injection current is very low. Similarly to sample A, increasing the injection current induces the simultaneous transitions of the $n=1$ and $n=2$ states. However, the emission corresponding to the $\mathrm{In}_{0.67} \mathrm{Ga}_{0.33} \mathrm{As}_{0.72} \mathrm{P}_{0.28} \mathrm{QWs}$ appears at lower injection current than for sample A. Further increase of the injection current causes the emission corresponding to the $n=1$ transition in the $\mathrm{In}_{0.67} \mathrm{Ga}_{0.33} \mathrm{As}_{0.72} \mathrm{P}_{0.28} \mathrm{QWs}$ to grow significantly. The variation of the spectral width with the injection current for samples A-C is shown in Fig. 3. It is clear that sample A has the broadest spectral width and sample B has the narrowest spectral width.

Table 1. Calculated Transition Wavelengths Corresponding to the Bounded Energy States of the Nonidentical MQWs of the Three Samples

\begin{tabular}{ccc}
\hline & $\begin{array}{c}\text { 8.7-nm } \operatorname{In}_{0.53} \mathrm{Ga}_{0.47} \mathrm{As} \\
n\end{array}$ & $\begin{array}{c}6.0-\mathrm{nm} \mathrm{In}_{0.67} \mathrm{Ga}_{0.33} \mathrm{As}_{0.72} \mathrm{P}_{0.28} \\
\text { Driple QW } \mathrm{QW}(\mu \mathrm{m})\end{array}$ \\
\hline 1 & 1.54 & 1.30 \\
2 & 1.46 & 1.24 \\
3 & 1.18 & Unbounded \\
\hline
\end{tabular}
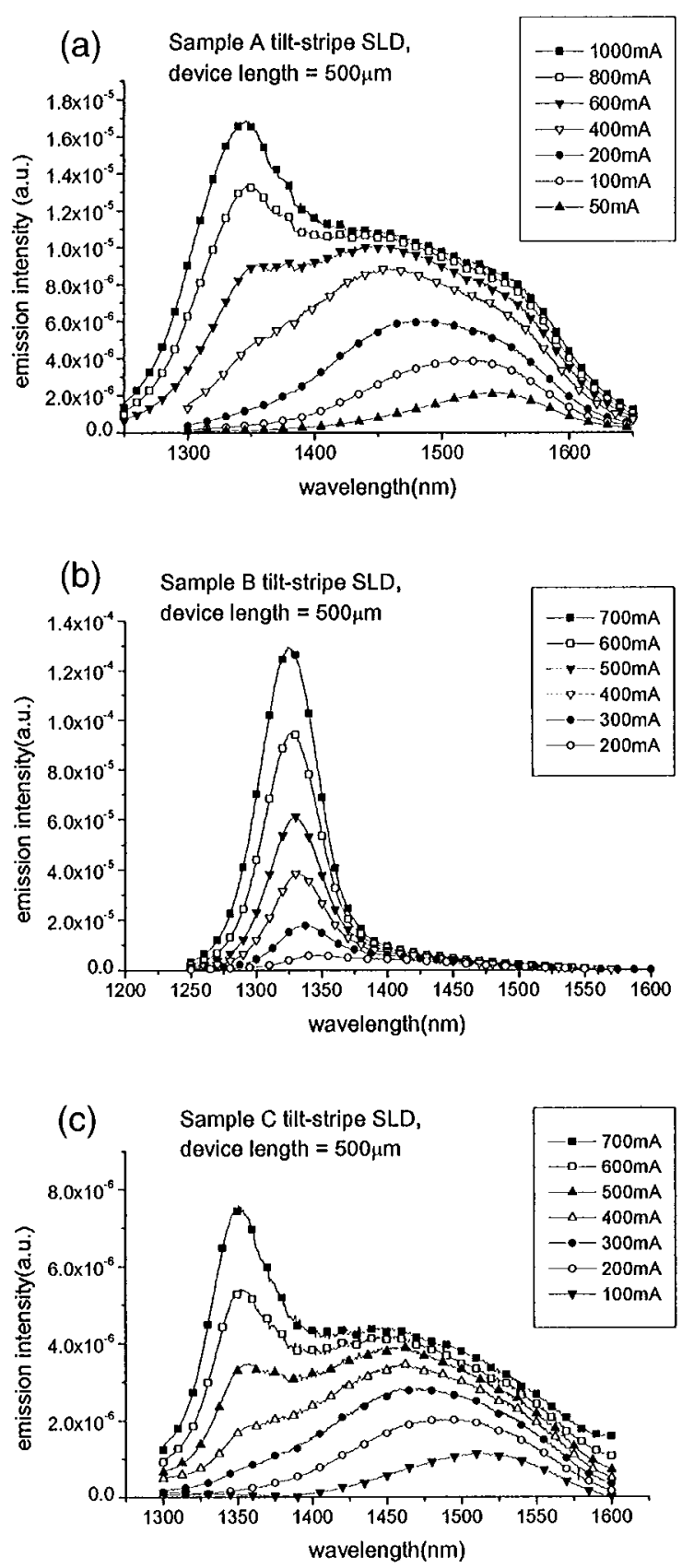

Fig. 2. Measured emission spectra of the three samples at different current levels. 


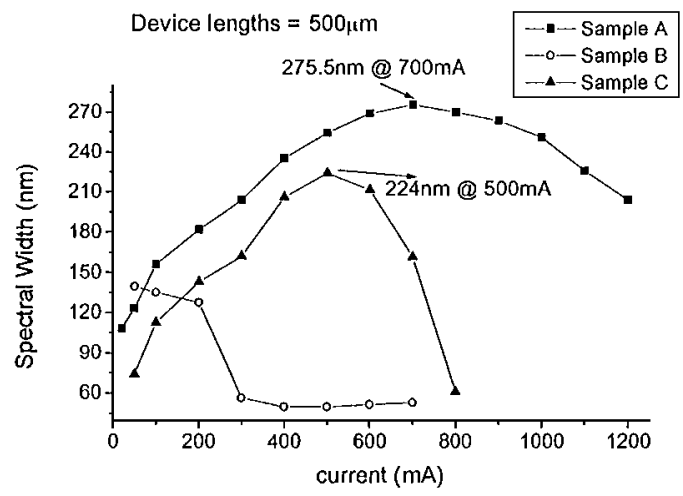

Fig. 3. Variation of spectral width with injection current for the three samples.

The emission characteristics shown above are obviously related to the sequential capture of carriers by the MQWs. When the devices are forward biased, electrons are injected from the $n$-cladding layer and holes are injected from the other direction in the MQW structures. These carriers are then captured by the QWs in the order that the carriers encounter them. According to the measured spectra, the wells near the $n$-cladding layer trap most of the carriers. Therefore, the 8.7-nm $\mathrm{In}_{0.53} \mathrm{Ga}_{0.47} \mathrm{As}$ QWs near the $n$-cladding layer (sample A) contribute to the emission first. When injection current increases, the carriers overflow to $\mathrm{In}_{0.67} \mathrm{Ga}_{0.33} \mathrm{As}_{0.72} \mathrm{P}_{0.28} \mathrm{QWs}$ for emission near $1.3 \mu \mathrm{m}$. Theoretical calculation shows that the total gain of the three $\mathrm{In}_{0.67} \mathrm{Ga}_{0.33} \mathrm{As}_{0.72} \mathrm{P}_{0.28} \mathrm{QWs}$ increases much faster than the total gain of the two $\mathrm{In}_{0.53} \mathrm{Ga}_{0.47} \mathrm{As} \mathrm{QWs}$ for large numbers of injected carriers. Thus the three $\operatorname{In}_{0.67} \mathrm{Ga}_{0.33} \mathrm{As}_{0.72} \mathrm{P}_{0.28} \mathrm{QWs}$ dominate the emission when the injection current is larger than $600 \mathrm{~mA}$. Similarly, sample $\mathrm{C}$ has emission that is dominated by the three $\operatorname{In}_{0.67} \mathrm{Ga}_{0.33} \mathrm{As}_{0.72} \mathrm{P}_{0.28}$ QWs when the injection current is larger than $500 \mathrm{~mA}$. Because some $\mathrm{In}_{0.67} \mathrm{Ga}_{0.33} \mathrm{As}_{0.72} \mathrm{P}_{0.28}$ QWs of sample $\mathrm{C}$ are closer to the $n$-cladding layer, the corresponding emission occurs at a lower injection current. For samples $\mathrm{A}$ and $\mathrm{C}$, the measured spectra reveal that the carrier distribution also depends on the injected carrier level. For sample B, because all three $\mathrm{In}_{0.67} \mathrm{Ga}_{0.33} \mathrm{As}_{0.72} \mathrm{P}_{0.28} \mathrm{QWs}$ are close to the $n$-cladding layer, carriers accumulated therein increase rapidly and have significant gain for emission. In contrast, since the $\operatorname{In}_{0.53} \mathrm{Ga}_{0.47} \mathrm{As}$ QWs near the $p$-cladding layer trap a smaller number of carriers, they have no chance to cause emission. Devices with a length of $700 \mu \mathrm{m}$ were also fabricated and measured. Their emission characteristics were similar to those of $500-\mu \mathrm{m}$ devices.

Our experiments show that the wells near the $n$-cladding layer accumulate more carriers than those near the $p$-cladding layer. This result is different from past observations ${ }^{10,11}$ that were attributed to the slow mobility of holes. From our new discovery, we conclude that other factors could be influential as well. In some discussions ${ }^{8,9,13}$ it was pointed out that carrier diffusion is also an important factor for nonuniform carrier distribution. Thus the reason that more carriers are trapped in QWs near the $n$-cladding layer possibly is due to the thick SCH layer in our devices. Because holes have a small diffusion constant, they need a much longer diffusion time than electrons to reach the $\mathrm{QW}$ region. Before the steady state is reached, electrons first move into the QWs near the $n$-cladding layer and establish a field that impedes further transport of electrons to other wells, In addition, this field tends to pull holes toward the well in which the electrons first reside. As a result, the QWs near the $n$-cladding layer accumulate more carriers, as evidenced by our spectral measurement. The wide barriers in our design also help to enhance the nonuniform distribution of carriers and cause the sequence influence of wells to be more prominent.

In conclusion, the sequence of nonidentical MQWs has been experimentally shown to have a significant influence on the emission spectra. With proper design of nonidentical MQWs made from InGaAsP/InP materials, extremely broadband emission from SLDs is possible. Our fabricated SLDs demonstrate what we believe to be record broadband characteristics. The emission spectrum could cover from less than 1.3 to nearly $1.55 \mu \mathrm{m}$, with the FWHM near $300 \mathrm{~nm}$. We have also discovered that $n$-side QWs could accumulate more carriers than $p$-side QWs. This is attributed to the thick $\mathrm{SCH}$ layer in our devices.

This work was supported in part by National Science Council, Taipei, Taiwan, under contracts NSC89-2215-E-002-016 and NSC89-2112-M-002-034. C.-F. Lin's e-mail address is cflin@cc.ee.ntu.edu.tw.

\section{References}

1. A. T. Semenov, V. R. Shidlovski, and S. A. Safin, Electron. Lett. 29, 854 (1993).

2. T. R. Chen, L. Eng, Y. H. Zhuang, and A. Yariv, Appl. Phys. Lett. 56, 1345 (1990).

3. C.-F. Lin, B.-L. Lee, and P.-C. Lin, IEEE Photon. Technol. Lett. 8, 1456 (1996).

4. X. Zhu, D. Cassidy, M. Hamp, D. Thompson, B. Robinson, Q. Zhao, and M. Davies, IEEE Photon. Technol. Lett. 9, 1202 (1997).

5. H. S. Gingrich, D. R. Chumney, S.-Z. Sun, S. D. Hersee, L. F. Lester, and S. R. Brueck, IEEE Photon. Technol. Lett. 9, 155 (1997).

6. C.-F. Lin and B.-L. Lee, Appl. Phys. Lett. 71, 1598 (1997).

7. T. F. Krauss, G. Hondromitros, B. Vogele, and R. M. De La Rue, Electron. Lett. 33, 1142 (1997).

8. N. Tessler and G. Eisenstein, IEEE J. Quantum Electron. 29, 1586 (1993).

9. R. Nagarajan, T. Fukushima, S. W. Corzine, and J. E. Bowers, Appl. Phys. Lett. 59, 1835 (1991).

10. H. Yamazaki, A. Tomita, M. Yamaguchi, and Y. Sasaki, Appl. Phys. Lett. 71, 767 (1997).

11. B.-L. Lee, C.-F. Lin, J.-W. Lai, and W. Lin, Electron. Lett. 34, 1230 (1998).

12. D. Ahn and S. L. Chuang, IEEE J. Quantum Electron. 26, 13 (1990).

13. M. Alam and M. Lundstrom, IEEE Photon. Technol. Lett. 6, 1418 (1994). 